\title{
Why Public Dissemination of Science Matters: A Manifesto
}

\author{
David M. Eagleman \\ Department of Neuroscience, Baylor College of Medicine, Houston, Texas 77030
}

\begin{abstract}
Communicating science to the public takes time away from busy research careers. So why would you do it? I here offer six reasons. First, we owe that understanding to the people who fund our experiments, the taxpaying public. Second, we can leverage our skills as scientists to inspire critical thinking in public and political dialog. Third, researchers are optimally positioned to stem the flow of scientific misinformation in the media. Fourth, we can explain the ways and the means by which science can (and cannot) improve law and social policy. Fifth, it is incumbent upon us to explain what science is and is not: while it is a way of thinking that upgrades our intuitions, it also comes with a deep understanding of (and tolerance for) uncertainty. Finally, we find ourselves in the pleasurable position of being able to share the raw beauty of the world around us - and in the case of neuroscience, the world inside us. I suggest that scientists are optimally stationed to increase their presence in the public sphere: our training positions us to synthesize large bodies of data, weigh the evidence, and communicate with nuance, sincerity and exactitude.
\end{abstract}

\section{Introduction}

Moving science from the cloisters of academia into the mainstream of public dialog can carry costs. It requires the expenditure of time and effort that could be invested in the laboratory. In a competitive field, every moment counts for manuscripts and grants. And there are social risks as well: many scientists admit concern about criticism from colleagues for forays into the public sphere.

So why do it?

Received June 17, 2013; accepted June 19, 2013.

Correspondence should be addressed to Dr. David Eagleman, Department of Neuroscience, Baylor College of Medicine, Houston, TX 77030.E-mail: david@eaglemanlab.net.

DOI:10.1523/JNEUROSCI.2556-13.2013

Copyright $\odot 2013$ the authors $\quad 0270-6474 / 13 / 3312147-03 \$ 15.00 / 0$
Here are six opportunities afforded by the public dissemination of science:

\section{Thank your funders}

Taxpayers around the nation labor away so that we can have the luxury of exploring our questions with passion. The investment in science tends to pay good returns for governments (Eagleman, 2013), but we must constantly remind the voting public why and how. We cannot reasonably ask funders to continuously contribute to a field that is taciturn or un-interpretable. While it is true that sites like PubMed Central make federally funded scientific publications available to the public, let's not fool ourselves into thinking that mere availability of first source material will automatically translate into digestion, synthesis, and understanding by the interested taxpayer. Would you invest billions in an industry that doesn't share its accomplishments, landmarks, open questions, and goals?

\section{Inspire critical thinking}

Police hire handwriting experts to tell them that a loopy letter can indicate who is a sex offender and who is not; the FBI and CIA hire mentalists to remotely see the contents of enemy bunkers; local detectives hire psychics to divine the whereabouts of stolen goods and lost children. Beyond the pity of flushing tax money on charlatanry, the fact that clairvoyants are commissioned by those with power and uniforms boosts their credibility.

For reasons of utility, expense, and expectations, it would be better if knowledge about the scientific method saturated deeply into the squares and capitols of our nations. The goal would be to inspire critical thinking. The end result would be to embarrass away non-evidence-based approaches. Debunking fuzzy thinking is part of the opportunity of your position; it is also part of the obligation.

A story from Adlai Stevenson's 1956 presidential campaign recounts that a woman from the audience shouted to him: "Senator, you have the vote of every thinking person!" Stevenson called back: "That's not enough, madam, we need a majority!" More than a funny tale, this should remind us that we all have a responsibility in the intellectual makeup of our countries.

\section{Stem the flow of bad information}

While media channels have a great hold on public dialog, they do not always get the facts straight. Practicing scientists cringe when the protagonist in a movie spouts a line that reverses the work we've invested in the name of evidence and clarity. But remember that it's our own faults. The producers don't have our years of training. We need to be sharing more with them; we need to inspire them to care about the value of validity.

As an example of why it matters, consider shows like CSI: Crime Scene Investigation. The fancy technologies on display have led to the "CSI effect," in which jurors in real criminal cases hold the expectation that police should be able to solve crimes effortlessly, via the help of photo enhancement, analysis of biological samples, magic tricks with DNA, and so on-thereby changing the jury's likelihood of conviction on erroneous grounds (Schweitzer and Saks, 2006).

In the new Sherlock Holmes series on $\mathrm{BBC}$, the young Holmes responds to a taunt of "psychopath!" from an officer. He whirls around and says: "I'm not a psychopath, I'm a high-functioning sociopath. Do your research.” Unfortunately, despite Holmes' otherwise stellar acumen, the terms psychopath and sociopath are synonymous. And really, he doesn't fit the description in any case. A science advisor would have helped. So would more dissemination of science in the public realm.

Similarly, the condition of synesthesia was highlighted in a recent episode of Criminal Minds. In this Hollywood portrayal, the killer had visual experiences 
triggered by the words people spoke. If the words he saw were orange, he knew the person was lying. If he saw white, they were telling the truth. He saw red if they were evil and deceptive. It was a nice sensory twist to move the plot forward, but scientifically senseless.

These shows need creative license, and we love them because of their wide-ranging imagination. But if it frustrates you when the facts are incorrect, don't simply complain. Let that energy inspire you to put your scientific voice into the mix.

\section{Inform public policy}

In October of 2011, Pinellas County in Florida voted to eliminate fluoride from its water supplies. Why? Because the voting commission was beset by citizens who viewed water fluoridation as "an unnecessary, even malevolent, form of government intervention" (Phillips, 2012). According to an article in the Tampa Bay Times, "some accused the board of trying to medicate them into submission; some warned that fluoridation was a Nazi policy designed to kill off undesirables; and some claimed that their skin ailments and other medical problems stemmed from fluoride." One mother, a resident of Tampa, volunteered her summary of the situation: "this is terrorism at the highest."

I'm not suggesting that governments are incapable of proposing ignorant or dastardly policies, but I am suggesting that a higher level of public science discourse can usefully anchor such discussions, affixing them to a bedrock of data rather than letting them float unmoored in waterways of opinion.

Recent decades have witnessed the same story played out repeatedly: recall the powerful suspicions about vaccinetriggered autism, cell-phone triggered brain tumors, and so on. All of these stories should remind us of the usefulness of attaching the conversation to a scaffolding of best evidence. And it's our responsibility to make that happen.

As one example, a new hotspot for public misunderstanding has arisen in the realm of criminal justice (Eagleman, 2011). This can be seen in the widespread confusion about the capacities and promises of brain imaging for the legal system. For example, a recent issue of Time magazine bragged the title "What makes us Good/Evil" above a false-colored midsagittal brain slice. The brain scan image had two pictures floating above it- one of Gandhi, one of Hitler. Both photos pointed to different spots in the brain, implying that activation in a particular re- gion of interest (or generously, a network) could determine whether someone was doomed to one of these binary categories. This is a troublesome notion. Behavior depends on context. The idea that a measurement of the brain could tell us what someone is going to do in the near future (as implied by the content of the article) is not only incorrect, but also morally perilous.

Beyond the issue of misunderstandings, there is an even more general point that needs to be made. There is no reason our governments shouldn't be able to run our social policy as rigorously as we run any other kind of experiment in the laboratory. As a colleague recently wrote in The Guardian: "How can you tell if a policy is working? Run a trial" (Goldacre, 2011). This is our responsibility. Instead of letting legislation ride on the winds of intuition and reaction, let's make our legislation evidence-based.

Now, this is not to promise that science can provide all the answers; it is instead a method for refining our intuitions. And this leads to the next point.

\section{Clarify what science is and is not}

Picture this scenario: a country sets up a National Commission for the Forecast and Prevention of Major Risks. The directive is simple: predict catastrophes. Now imagine that one morning there are small trembles, and the scientists' are called upon to speculate whether a bigger quake is to follow. They decide to make the call not to evacuate, concluding, to the best of their limited ability, that a bigger quake is not forthcoming.

Imagine they are wrong, and as a result they are put on trial, found guilty, and thrown in jail.

This actually happened. On April 6, 2009, the L'Aquila quake in Italy killed 309 people, and six of Italy's leading geophysicists were found guilty of manslaughter.

The problem is that earthquakes, while common in that region, are unpredictable. In an interview with the BBC, Malcolm Sperrin, director of medical physics at the United Kingdom's Royal Berkshire Hospital, said, "If the scientific community is to be penalized for making predictions that turn out to be incorrect, or for not accurately predicting an event that subsequently occurs, then scientific endeavor will be restricted to certainties only and the benefits that are associated with findings from medicine to physics will be stalled" (Johnston, 2012).

It is critical for the public to have an appreciation of the uncertainty inherent in the scientific process. An appreciation of multiple hypotheses and the interpretation of probability is part of the scientific temperament (Eagleman, 2010), but that does not always translate into the public interpretation of science.

Consider the heated issue of climate change. A nonscientist friend of mine recently suggested that the government should set up a single body of scientists who can "simply tell the public what the right answers are." It's a nice idea, but misguided: scientists often don't know, and commonly don't agree.

If this simple fact were more widely understood on a societal level, it could lead to nimble social policy. In such a world, regulations could rapidly adapt to new, incoming information, instead of ossifying under the political pretense that there is a single right answer.

Science takes complex networks of observations and attempts to simplify them into an overarching narrative. It is not clear there is a true answer, only the answer that best fits the facts at any time. Newtonian physics has proven very useful, but it later became clear that it is a subset of Einsteinian physics. Presumably, this will also be understood at some point as a subset of a larger framework.

As the science communicator Alan Alda said in a recent interview: "I think it's a danger to create the illusion of certainty. Because science, it seems to me, thrives on uncertainty. One of the great personal benefits I've had from reading science and listening to scientists talk is to appreciate the pleasure of uncertainty" (Cho, 2012).

\section{Share the raw beauty of the scientific pursuit}

What gives pleasure to a life in science? Beyond the possibility of contributing to wellness and combating disease, a life in science offers an appreciation of the overwhelming grandeur of the world around and inside of us: the mysteries, the principles, the codes that are beyond what we can currently conceive. In the same way a conductor shares music, a scientist is driven to share the protean, untapped, omnipresent beauty of the world. Science is not just about the generation of facts; it is about opening our eyes to the vastness of our ignorance and sharing the inspiration for further discovery.

\section{Conclusion}

Why should you spend a portion of your time disseminating information to the broader public? Beyond the six reasons I outlined above, there is one more: you are well set up for it. You have been trained to think with rigor, to integrate large bodies 
of data, to weigh evidence, to value intellectual humility, to retain nuance when speaking about complex issues, and to write precisely what you mean to say.

So speak up. The future needs your voice.

\section{References}

Cho A (2012) Alan Alda challenges scientists to explain: what is time? Science Insider (December 12, 2012). Available: http:// news.sciencemag.org/scienceinsider/2012/12/ alan-alda-challenges-scientists-.html.

Eagleman DM (2010) Why I am a possibilian. New Scientist 207:34-35.

Eagleman DM (2011) The brain on trial. The Atlantic. pp. 7.

Eagleman DM (2013) What our brains can teach us. The New York Times (February 22, 2013). pp. A17.

Goldacre B (2011) How can you tell if a policy is working? Run a trial. The Guardian (May 13, 2011). pp. 44.
Johnston A (2012) L'Aquila quake: Italy scientists guilty of manslaughter. BBC News. Available: http://www.bbc.co.uk/news/world-europe20025626.

Phillips AM (2012) Pinellas county commission votes 6-1 to return fluoride to drinking water. Tampa Bay Times (November 27, 2012).

Schweitzer NJ, Saks MJ (2006) The CSI effect: popular fiction about forensic science affects the public's expectations about real forensic science. Jurimetrics 47:357-364. 